\title{
Electrocardiographic findings of the effects of beta-blockers
}

Andie Hartanto $\underline{\text { Djohan }}^{1}$, MBBS, MRCP, Ching-Hui Sia ${ }^{1,2}$, MBBS, MRCP, William Kok-Fai Kong ${ }^{1,2}$, MD, Kian-Keong $\underline{P o h}^{1,2}$, MBBChir, FACC

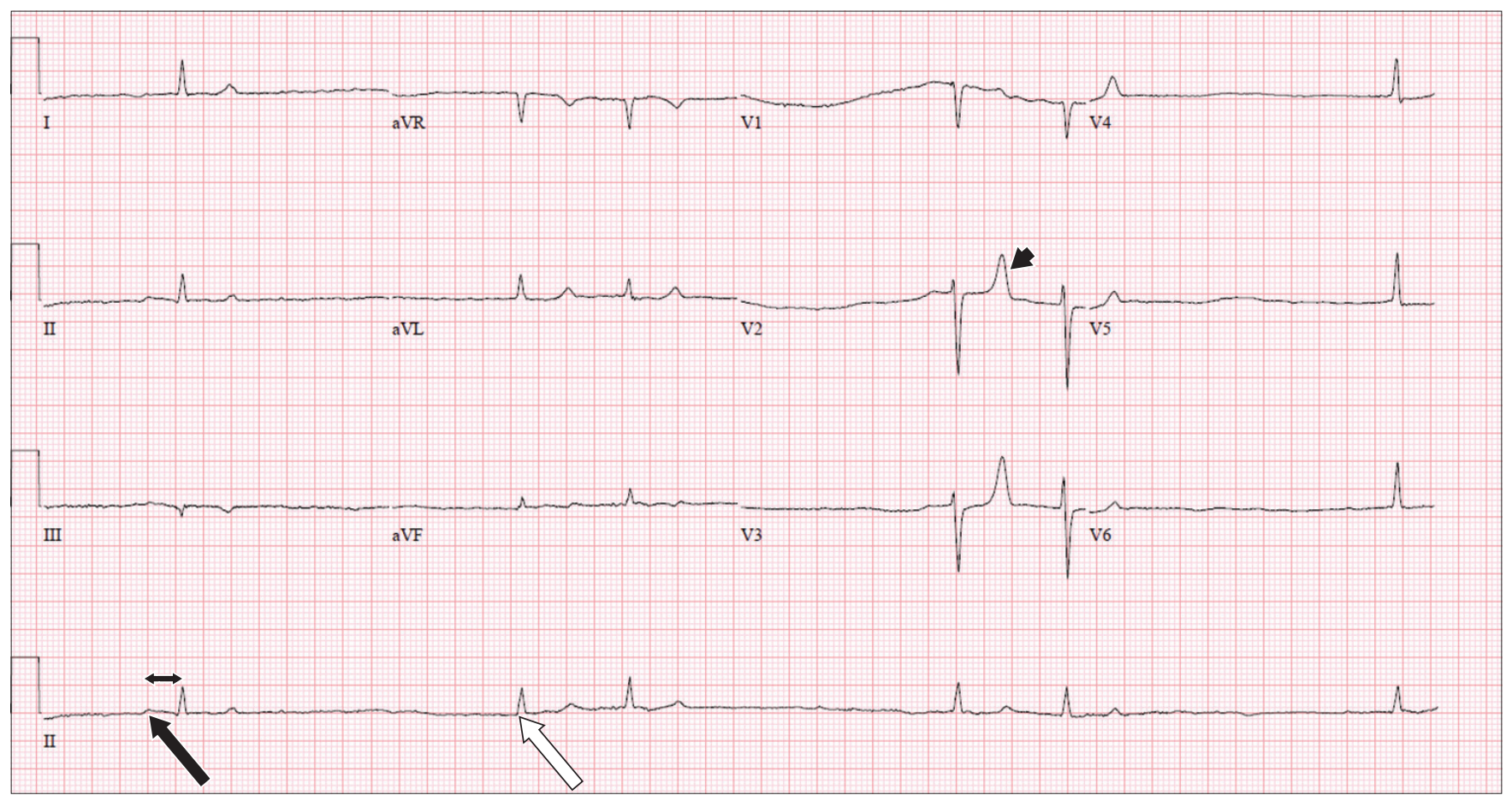

Fig. 1 Case 1: Initial ECG on admission performed after resuscitation.

\section{CASE 1}

\section{CLINICAL PRESENTATION}

An 85-year-old woman presented to the emergency department with drowsiness on a background of functional decline of two weeks' duration. Her medical history was significant for hypertension and hyperlipidaemia, for which she was on regular follow-up. Medications included amlodipine $10 \mathrm{mg}$ OM (every morning), atenolol $100 \mathrm{mg} \mathrm{OM}$, atorvastatin $20 \mathrm{mg}$ ON, frusemide $40 \mathrm{mg}$ OM, prazosin $0.5 \mathrm{mg}$ BD (twice daily) and valsartan $160 \mathrm{mg}$ OM. The patient was drowsy with Kussmaul breathing prior to a transient period of asystole noted on the cardiac monitor. Immediate resuscitation was performed with return of spontaneous circulation after 10 seconds.

Initial investigations showed decompensated metabolic acidosis ( $\mathrm{pH} 7.14$, partial pressure of carbon dioxide $24 \mathrm{mmHg}$, bicarbonate $8.4 \mathrm{mmol} / \mathrm{L}$ ) with hyperkalaemia $(6.9 \mathrm{mmol} / \mathrm{L})$, for which she was treated with calcium gluconate, insulin and dextrose. What did her admission electrocardiogram (ECG) show (Fig. 1)?

\section{ECG INTERPRETATION}

Fig. 1 shows sinus node dysfunction with intermittent sinus $\mathrm{P}$ waves (black arrow) with first-degree atrioventricular block (double-headed arrow), as well as intermittent junctional escape beats (white arrow). Tall, tented T-waves (arrowhead) were observed in leads V2 and V3.

Fig. 2 shows a rhythm strip obtained from the cardiac monitor when the patient was paced transcutaneously. Pacing spikes are observed before each QRS complex (arrows).

\section{CLINICAL COURSE}

The patient's hypotensive and bradycardic episodes persisted following resuscitation despite initiation and titration of intravenous dopamine to $20 \mathrm{mcg} / \mathrm{kg} / \mathrm{min}$. Further investigations

${ }^{1}$ Department of Cardiology, National University Heart Centre Singapore, ${ }^{2}$ Yong Loo Lin School of Medicine, National University of Singapore, Singapore

Correspondence: Dr Andie Hartanto Djohan, Senior Resident, Department of Cardiology, National University Heart Centre Singapore, 1E Kent Ridge Rd, NUHS Tower Block Level 9, Singapore 119228. andie_hartanto_djohan@nuhs.edu.sg 


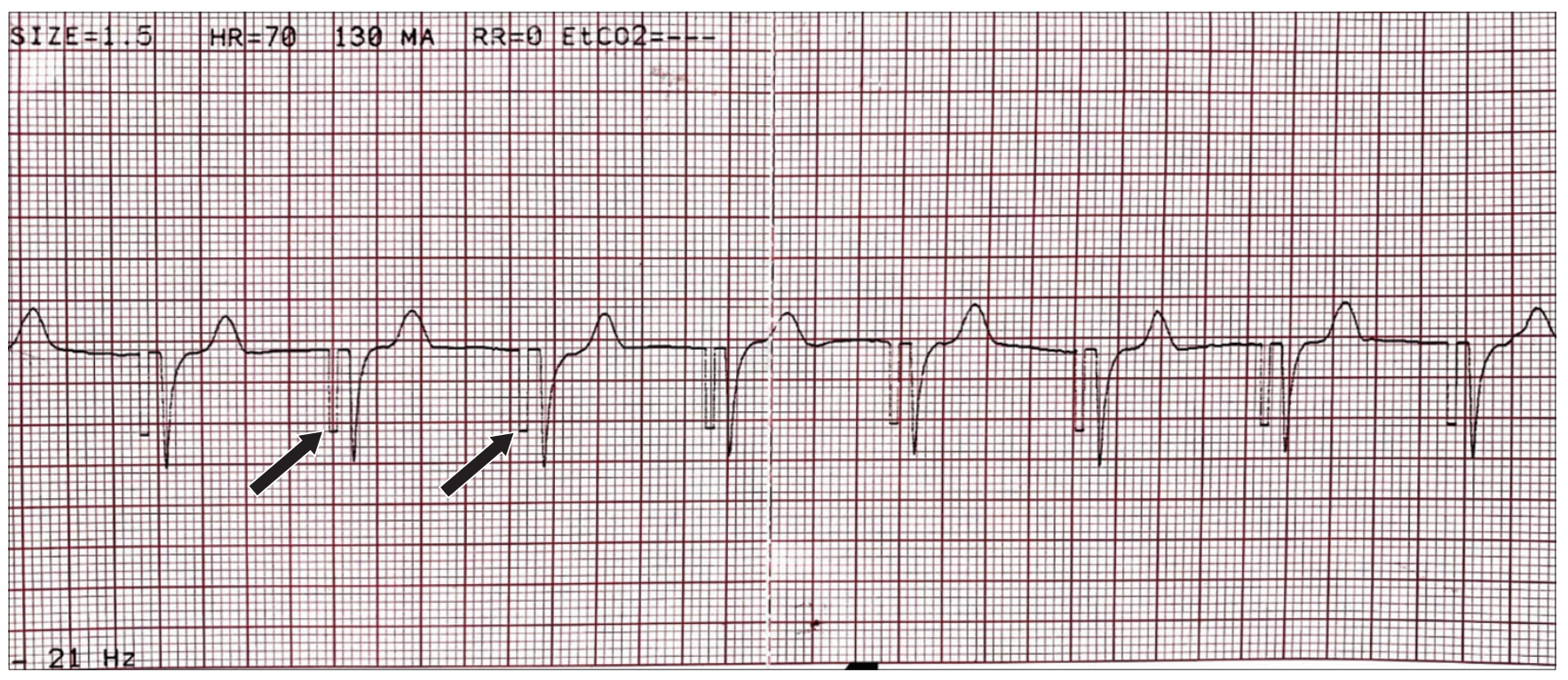

Fig. 2 Case 1: Rhythm strip on ECG shows transcutaneous pacing, with arrows indicating pacing spikes.

revealed acute kidney injury, with an elevated creatinine level of $853 \mu \mathrm{mol} / \mathrm{L}$ from a baseline of $65 \mu \mathrm{mol} / \mathrm{L}$. The patient was then intubated for airway protection, started on inotropic support and administered intravenous glucagon. She was also commenced on transcutaneous pacing (TCP) at 70 beats per minute (bpm) (Fig. 2). The working diagnosis was cardiogenic shock secondary to the beta-blocker (BB) atenolol, which was attributed to acute kidney injury. The patient was then admitted to the intensive care unit, where continuous renal replacement therapy (CRRT) was initiated.

The patient's intrinsic cardiac rhythm improved following two days of CRRT, with an improvement in her heart rate. The TCP backup pacing and inotropes were gradually weaned and stopped after four days, and the patient became haemodynamically stable without support. Atenolol was also stopped since admission.

\section{CASE 2}

\section{CLINICAL PRESENTATION}

A 53-year-old man with a significant medical history of Type 2 diabetes mellitus, hypertension, hyperlipidaemia, chronic kidney disease and ischaemic heart disease presented with nonST elevation myocardial infarction on a background of septic shock and acute-on-chronic kidney injury/disease (AoCKD). His medications included aspirin $100 \mathrm{mg}$ OM, clopidogrel $75 \mathrm{mg}$ OM, carvedilol $6.25 \mathrm{mg}$ BD, atorvastatin $40 \mathrm{mg}$ ON and frusemide $80 \mathrm{mg}$ TDS (three times a day). The patient developed haemodynamically significant bradycardia despite being administered intravenous dopamine of $20 \mathrm{mcg} / \mathrm{kg} / \mathrm{min}$. What does the ECG (Fig. 3) that was obtained at the onset of deterioration show?

\section{ECG INTERPRETATION}

Fig. 3 shows marked sinus bradycardia at a rate of $40 \mathrm{bpm}$, with first-degree heart block. There is a $\mathrm{P}$ wave (circles) preceding each QRS complex, and the PR interval (double-headed arrow) is prolonged at approximately $220 \mathrm{~ms}$.
Fig. 4 shows a ventricular-paced rhythm, as evidenced by the small pacing spike (black arrows) just preceding its QRS complex (white arrowheads). We were able to localise the position of the pacing wire in the right ventricular (RV) apex owing to the left bundle branch block morphology of depolarisation on the precordial leads (black arrowheads) and negative QRS polarity on the inferior limb leads II, III and aVF (white arrows). The RV apex location of the transvenous pacing (TVP) tip was confirmed via chest radiograph, as observed in Fig. 5 (circle).

\section{CLINICAL COURSE}

The patient remained haemodynamically unstable on intravenous infusion of dopamine of $20 \mathrm{mcg} / \mathrm{kg} / \mathrm{min}$ and was started on TCP. This resulted in improvement of haemodynamics. Laboratory investigations revealed progression of AoCKD. Review of drug charts also revealed that the patient had been consistently administered carvedilol $6.25 \mathrm{mg}$ BD during his inpatient stay. A diagnosis of haemodynamically significant bradycardia secondary to carvedilol retention on a background of poor renal clearance owing to AoCKD was established. The patient was sent to the coronary care unit for immediate TVP to augment cardiac output.

\section{DISCUSSION}

BBs are commonly used in general practice for a variety of medical conditions. Major society guidelines have indicated the use of BBs for the management of stable ischaemic heart disease, acute coronary syndrome, ${ }^{(1-3)}$ atrial fibrillation, ${ }^{(4)}$ atrial flutter, ${ }^{(4)}$ supraventricular tachycardia, ${ }^{(5)}$ ventricular tachycardia, ${ }^{(6)}$ hypertrophic cardiomyopathy ${ }^{(7)}$ and heart failure. ${ }^{(8)}$

\section{Pharmacokinetics}

The pharmacokinetic properties of BBs can be broadly divided into lipophilic and hydrophilic drugs. Lipophilic drugs (e.g. metoprolol, propranolol and timolol) are absorbed from the enteral route but undergo extensive hepatic first-pass metabolism, 


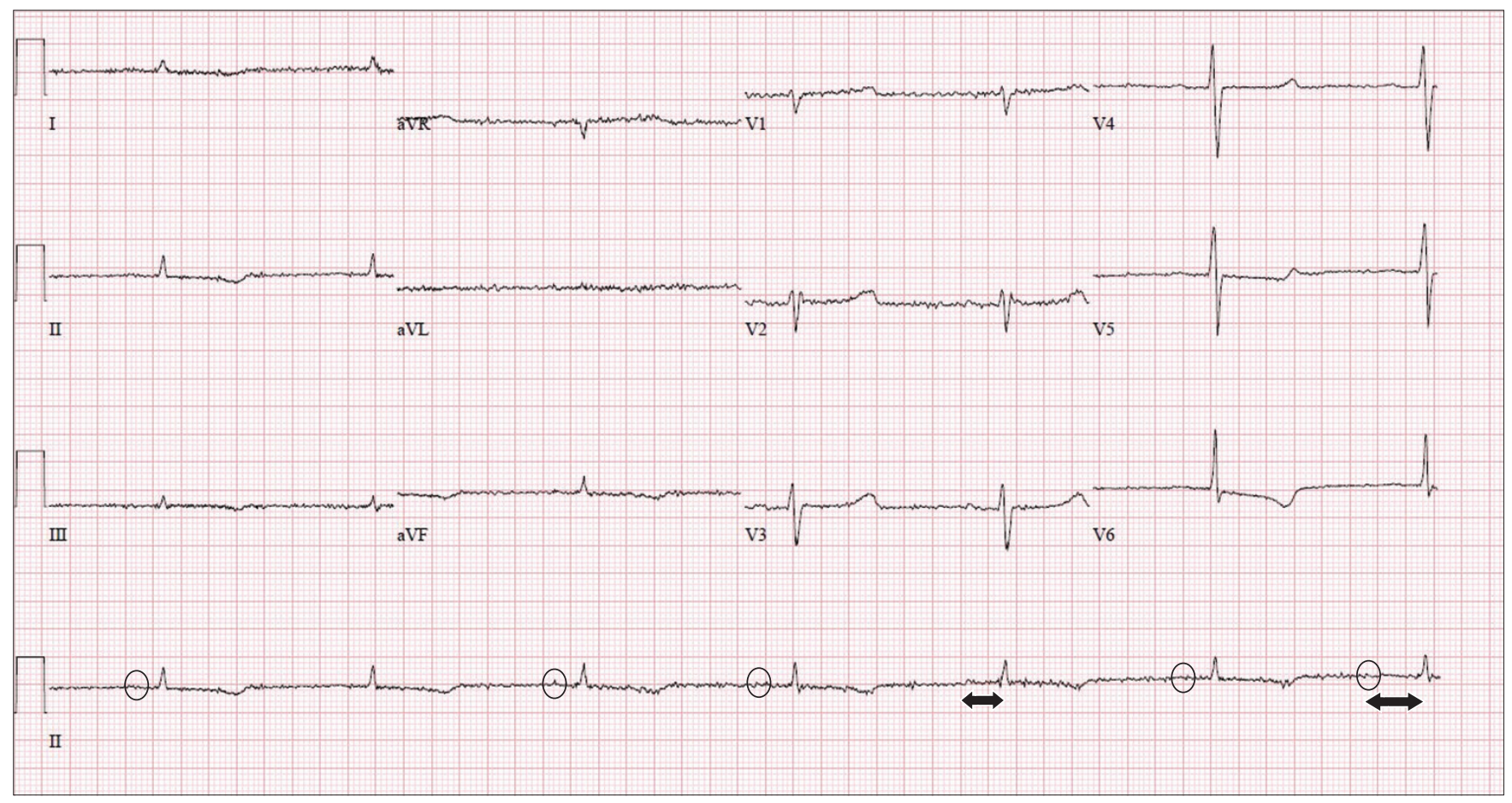

Fig. 3 Case 2: ECG at the onset of clinical deterioration.

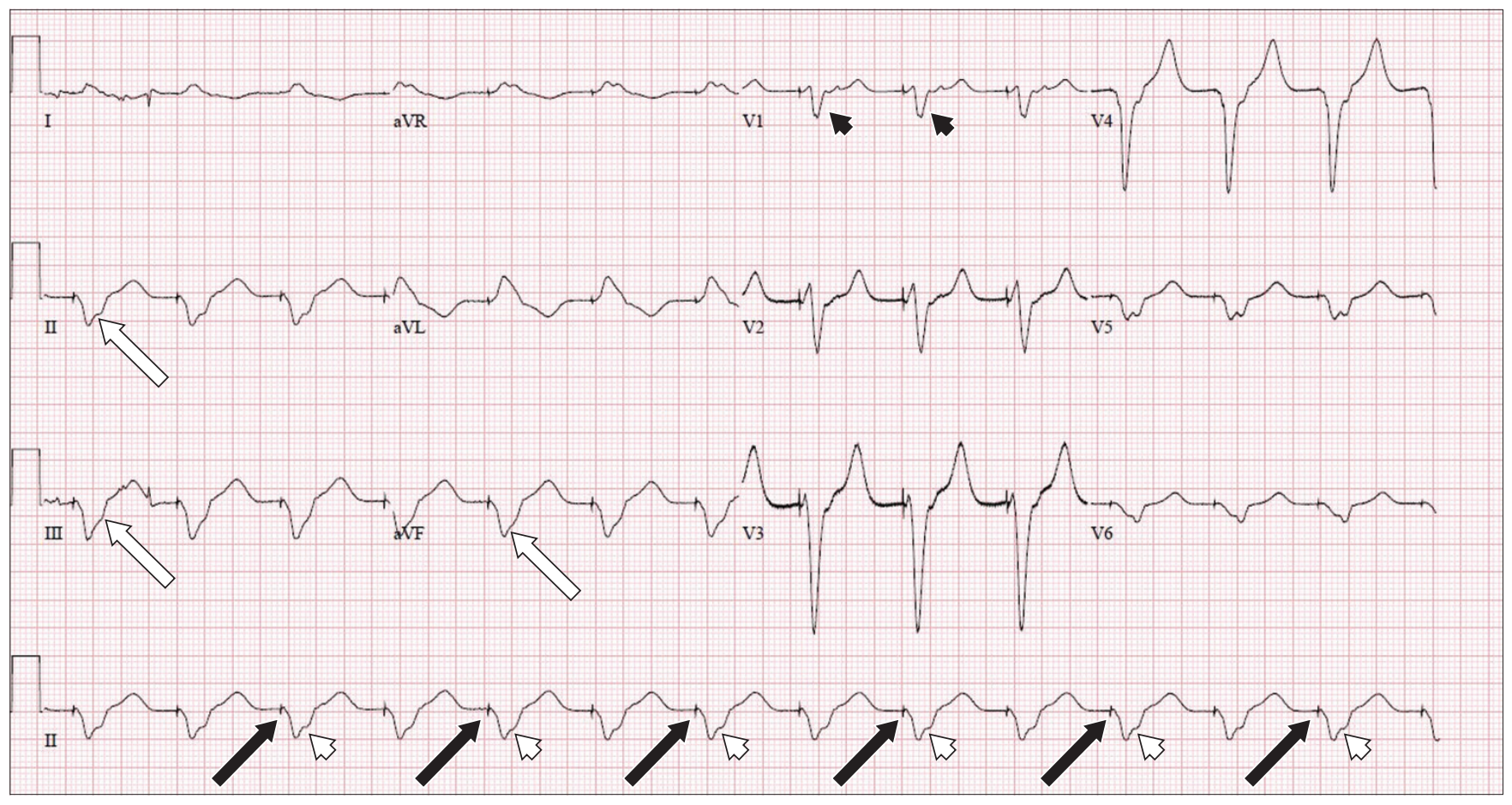

Fig. 4 Case 2: Electrocardiogram after transvenous pacing.

leading to low oral bioavailability (10\%-30\%). Hence, these drugs may accumulate in patients with reduced hepatic perfusion (e.g. elderly patients, or those with congestive cardiac failure or liver cirrhosis) (Table I). They have shorter elimination half-lives (1-5 hours) and may penetrate the blood-brain barrier, accounting for a greater incidence of central side effects. ${ }^{(9)}$

Conversely, hydrophilic drugs (e.g. atenolol and esmolol) are absorbed in their entirety from the gastrointestinal tract and
Table I. Pharmacokinetics of some commonly used beta-blockers. ${ }^{(10)}$

\begin{tabular}{|ll|}
\hline Drug & Hepatic metabolism (\%) \\
\hline Propranolol & 99 \\
\hline Timolol & 80 \\
\hline Sotalol & 40 \\
\hline Metoprolol & 97 \\
\hline Atenolol & $<10$ \\
\hline
\end{tabular}


Table II. Properties of beta-blockers in relation to renal function. ${ }^{(10)}$

\begin{tabular}{|c|c|c|c|c|c|c|c|}
\hline \multirow[t]{2}{*}{ Drug } & \multicolumn{2}{|l|}{ Half-life (hr) } & \multicolumn{4}{|c|}{ Dosage in renal failure GFR ( $\mathrm{mL} / \mathrm{min})$} & \multirow[t]{2}{*}{ Dialysability } \\
\hline & Normal renal function & Uraemia & $>50$ & $35-50$ & $15-35$ & $<15$ & \\
\hline Propranolol & $2-4$ & $2-3$ & Normal & Slight reduction & Slight reduction & Slight reduction & \\
\hline Timolol & $4-6$ & 4 & Normal & Slight reduction & Slight reduction & Slight reduction & \\
\hline Sotalol & $13-17$ & 42 & Normal & Normal & $50 \%$ dose & $25 \%$ dose & Moderate \\
\hline Metoprolol & $2.5-4.5$ & $2.5-4.5$ & Normal & Normal & Normal & Normal & High \\
\hline Atenolol & $6-9$ & 127 & Normal & Normal & $50 \%$ dose & $25 \%$ dose & High \\
\hline
\end{tabular}

GFR: glomerular filtration rate

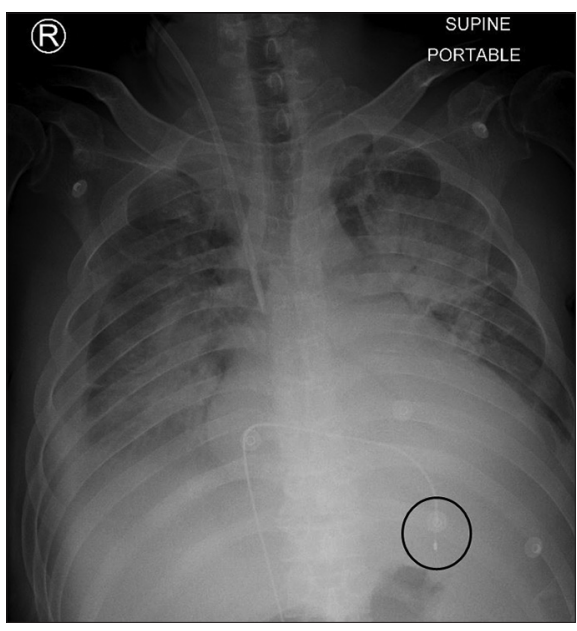

Fig. 5 Case 2: Chest radiograph after transvenous pacing.

are renally excreted unchanged or as active metabolites. These drugs do not readily cross the blood-brain barrier and have longer elimination half-lives (6-24 hours), which are further prolonged in case of a reduction in glomerular filtration rate (GFR) (i.e. elderly individuals, patients with renal insufficiency) (Table II). ${ }^{(9,10)}$

BBs such as bisoprolol exhibit equal hepatic and renal clearance (balanced clearance), ${ }^{(9)}$ while carvedilol has a low oral bioavailability owing to its extensive first-pass metabolism. It binds to plasma proteins and is eliminated hepatically. ${ }^{(11)}$

\section{Adverse events related to beta-blocker use}

In general, beta-adrenergic inhibitors are well tolerated. However, serious adverse events may still occur, especially when BBs are used in large doses, ${ }^{(9)}$ as briefly mentioned below.

\section{Cardiovascular}

BBs may cause haemodynamically significant bradycardia and AV block via their negative chronotropic and inotropic properties. Further, BBs may reduce peripheral tissue perfusion owing to unopposed stimulation of vascular alpha-adrenoceptors because of blockade of vascular beta-adrenoceptors, leading to peripheral vasoconstriction, Raynaud's phenomenon, impotence and deterioration of symptoms in patients with severe peripheral vascular disease. These side effects may be mitigated via the selection of agents with beta1-selectivity. BBs may also cause coronary vasospasm and ischaemia via their effect on increasing coronary vasomotor tone, again owing to unopposed alpha-adrenergic-mediated vasoconstriction. (9,11) $^{-1}$ Finally, abrupt discontinuation of BBs following long-term therapy may lead to rebound symptoms such as arrhythmias and angina. ${ }^{(12)}$

\section{Metabolic}

In patients with diabetes mellitus, non-selective BBs may hide manifestations of hypoglycaemia such as tremor and tachycardia. Hence, beta1-selective agents are preferred in this vulnerable patient population.

\section{Pulmonary}

Beta2-adrenoceptors are responsible for bronchodilation of the pulmonary tree, and BBs may cause life-threatening bronchoconstriction, hyper-reactivity and increased airway resistance. As a result, BBs are relatively contraindicated in patients with asthma and bronchospastic chronic obstructive pulmonary disease. ${ }^{(13}$

\section{Effects on the central nervous system}

Lipophilic BBs can cross the blood-brain barrier, leading to central nervous system (CNS) side effects such as fatigue, headache, insomnia, vivid dreams and depression. Clinicians may consider switching patients who experience these symptoms to a hydrophilic $\mathrm{BB}$, where CNS penetration and side effects are markedly reduced. ${ }^{(14)}$

\section{Management of symptomatic and/or haemodynamically unstable bradycardia}

While sinus and junctional bradycardia are generally benign, extreme bradycardia from asystole or prolonged sinus arrest or AV blocks may render a patient symptomatic and/or lead to haemodynamic instability, which warrants acute management.

\section{Pharmacological therapy}

Pharmacological therapy can be immediately started with agents that increase the sinus heart rate or the escape rhythm, such as atropine, isoprenaline, dopamine, dobutamine and adrenaline. ${ }^{(15)}$

\section{Transcutaneous pacing}

TCP is an effective but underused modality owing to the discomfort it causes to the patient. It is suitable as an emergency life-saving therapy or as backup for infrequent pacing. In Case 1, TCP was initiated for haemodynamically significant bradycardia despite using the maximal dose of intravenous dopamine infusion. We opted for TCP instead of TVP, as the bradycardia of the patient was reversible with dialysis, thus avoiding the potential complications of TVP. 


\section{Transvenous pacing}

Temporary TVP is an alternative to TCP but risks potentially serious complications such as infection, myocardial perforation and tamponade. The 2013 European Society of Cardiology guidelines on pacing suggest that TVP be used only when pharmacological therapy fails and that it be limited to cases of high-degree AV block without escape rhythm, life-threatening bradyarrhythmias or in acute settings (acute myocardial infarction, drug toxicity or concomitant systemic infection). ${ }^{(16)}$ In Case 2, a transvenous pacing wire was inserted into the RV apex, as the patient remained haemodynamically compromised despite receiving the maximal dose of intravenous infusion of dopamine.

\section{Haemodialysis}

Lastly, haemodialysis may be considered when patients have been haemodynamically stabilised and if there is a dialysable culprit drug leading to bradycardia. In Case 1, the patient was initiated on CRRT immediately upon stabilisation of her clinical parameters. It is of utmost importance to identify any potentially reversible causes of an unstable bradycardia and address them, as evidenced by Case 1, where patients could be weaned off TCP following clearance of supratherapeutic levels of atenolol.

\section{CONCLUSION}

In conclusion, despite the vast therapeutic indications of BBs, their use is associated with potentially life-threatening risks. Prompt recognition of the signs and symptoms as well as the predisposing factor of BB-related toxicities and instituting appropriate emergency medical therapy are of utmost importance in the face of an ageing population with multiple comorbidities and polypharmacy.

\section{REFERENCES}

1. O'Gara PT, Kushner FG, Ascheim DD, et al. 2013 ACCF/AHA guideline for the management of ST-elevation myocardial infarction: a report of the American College of Cardiology Foundation/American Heart Association Task Force on Practice Guidelines. Circulation 2013; 127:e362-425

2. Ineid H, Anderson JL, Wright RS, et al. 2012 ACCF/AHA focused update of the guideline for the management of patients with unstable angina/non-ST-elevation myocardial infarction (updating the 2007 guideline and replacing the 2011 focused update): a report of the American College of Cardiology Foundation/ American Heart Association Task Force on practice guidelines. Circulation 2012; 126:875-910.

3. Fihn SD Gardin JM, Abrams J, et al, 2012 ACCF/AHA/ACP/AATS/PCNA SCAI/STS guideline for the diagnosis and management of patients with stable ischemic heart disease: a report of the American College of Cardiology Foundation/American Heart Association task force on practice guidelines, and the American College of Physicians, American Association for Thoracic Surgery, Preventive Cardiovascular Nurses Association, Society for Cardiovascular Angiography and Interventions, and Society of Thoracic Surgeons. Circulation 2012; 126:e354-471

4. January CT, Wann LS, Alpert JS, et al. 2014 AHA/ACC/HRS guideline for the management of patients with atrial fibrillation: a report of the American College of Cardiology/American Heart Association Task Force on Practice Guidelines and the Heart Rhythm Society. I Am Coll Cardiol 2014; 64:e1-76.

5. Page RL, Joglar JA, Caldwell MA, et al. 2015 ACC/AHA/HRS guideline for the management of adult patients with supraventricular tachycardia: a report of the American College of Cardiology/American Heart Association Task Force on clinical practice guidelines and the Heart Rhythm Society. Circulation 2016; 133:e506-74.

6. Priori SG, Blomström-Lundqvist C, Mazzanti A, et al. 2015 ESC guidelines for the management of patients with ventricular arrhythmias and the prevention of sudden cardiac death: the Task Force for the management of patients with ventricular arrhythmias and the prevention of sudden cardiac death of the European Society of Cardiology (ESC). Endorsed by: Association for European Paediatric and Congenital Cardiology (AEPC). Eur Heart J 2015; 36:2793-867.

7. Elliott PM, Anastasakis A, Borger MA, et al. 2014 ESC guidelines on diagnosis and management of hypertrophic cardiomyopathy: the Task Force for the diagnosis and management of hypertrophic cardiomyopathy of the European Society of Cardiology (ESC). Eur Heart J 2014; 35:2733-79.

8. Ponikowski P, Voors AA, Anker SD, et al. 2016 ESC guidelines for the diagnosis and treatment of acute and chronic heart failure: the Task Force for the diagnosis and treatment of acute and chronic heart failure of the European Society of Cardiology (ESC). Developed with the special contribution of the Heart Failure Association (HFA) of the ESC. Eur Heart J 2016; 37:2129-200.

9. López-Sendón J, Swedberg K, McMurray J, et al. Expert consensus document on beta-adrenergic receptor blockers. Eur Heart J 2004; 25:1341-62.

10. Wilkinson R. Beta-blockers and renal function. Drugs 1982; 23:195-206.

11. Frishman WH. Carvedilol. N Engl J Med 1998; 339:1759-65.

12. Psaty BM, Koepsell TD, Wagner EH, LoGerfo JP, Inui TS. The relative risk of incident coronary heart disease associated with recently stopping the use of beta-blockers. JAMA 1990; 263:1653-7.

13. Chen J, Radford MJ, Wang Y, Marciniak TA, Krumholz HM. Effectiveness of beta-blocker therapy after acute myocardial infarction in elderly patients with chronic obstructive pulmonary disease or asthma. J Am Coll Cardiol 2001; 37:1950-6.

14. Salem SA, McDevitt DG. Central effects of beta-adrenoceptor antagonists. Clin Pharmacol Ther 1983; 33:52-7.

15. Burri H, Dayal N. Acute management of bradycardia in the emergency setting. Cardiovasc Med 2018; 21:98-104.

16. Brignole M, Auricchio A, Baron-Esquivias G, et al. 2013 ESC guidelines on cardiac pacing and cardiac resynchronization therapy: the task force on cardiac pacing and resynchronization therapy of the European Society of Cardiology (ESC). Developed in collaboration with the European Heart Rhythm Association (EHRA). Europace 2013; 15:1070-118. 


\section{SINGAPORE MEDICAL COUNCIL CATEGORY 3B CME PROGRAMME} (Code SMJ 202110B)

Question 1. Lipophilic beta-blockers include the following:
(a) Metoprolol
(b) Propranolol
(c) Timolol
(d) Atenolol

Question 2. The following drugs have predominantly renal clearance:
(a) Propranolol
(b) Metoprolol
(c) Atenolol
(d) Sotalol

Question 3. Indications for the use of beta-blockers include the following:
(a) Acute coronary syndrome
(b) Stable ischaemic heart disease
(c) Heart failure
(d) Supraventricular tachycardia

Question 4. Adverse events related to the use of beta-blockers include the following:

(a) Masking of hypoglycaemic symptoms (e.g. tremor, tachycardia)

(b) Impotence

(c) Peripheral vasoconstriction

(d) Coronary vasospasm and ischaemia

Question 5. Management of haemodynamically significant bradycardia includes the following:
(a) Atropine
(b) Dopamine
(c) Transcutaneous pacing
(d) Transvenous pacing

\section{Doctor's particulars:}

Name in full: MCR no.:

Specialty: Email:

\section{SUBMISSION INSTRUCTIONS:}

Visit the SMJ website: http://www.smj.org.sg/current-issue and select the appropriate quiz. You will be redirected to the SMA login page.

For SMA member: (1) Log in with your username and password (if you do not know your password, please click on 'Forgot your password?'). (2) Select your answers for each quiz and click 'Submit'.

For non-SMA member: (1) Create an SMJ CME account, or log in with your SMJ CME username and password (for returning users). (2) Make payment of SGD 21.40 (inclusive of $7 \%$ GST) via PayPal to access this month's quizzes. (3) Select your answers for each quiz and click 'Submit'.

\section{RESULTS:}

(1) Answers will be published online in the SMJ December 2021 issue. (2) The MCR numbers of successful candidates will be posted online at the SMJ website by 31 December 2021. (3) Passing mark is $60 \%$. No mark will be deducted for incorrect answers. (4) The SMJ editorial office will submit the list of successful candidates to the Singapore Medical Council. (5) One CME point is awarded for successful candidates. (6) SMC credits CME points according to the month of publication of the CME article (i.e. points awarded for a quiz published in the October 2021 issue will be credited for the month of October 2021, even if the deadline is in December 2021).

Deadline for submission (October 2021 SMJ 3B CME programme): 12 noon, 24 December 2021. 